\title{
Cervical and Lumbar Pain among Dental Interns in Saudi Arabia: A National Cross-sectional Study
}

\author{
Ayman M Sulimany
}

\begin{abstract}
Background: Previous evidence indicated that musculoskeletal disorders (MSDs) are highly prevalent among dentists. However, limited data are available on the prevalence and predictors for cervical and lumbar pain, the two most common subtypes of MSDs reported internationally. Aim and objective: The aim and objective of this nationwide cross-sectional study was to assess the prevalence and predictors of cervical and lumbar pain among dental interns in Saudi Arabia.

Materials and methods: Data were collected using an online survey that was distributed to dental interns who graduated during the 2018-2019 academic year from all dental schools in Saudi Arabia. The survey included questions related to sociodemographic characteristics, symptoms of MSDs, and ergonomic preventive practices. Bivariate and multivariate logistic regression analyses were performed to assess several predictors of cervical and lumbar pain among our sample population.

Results: Of the 1,552 eligible interns, 889 (57\%) completed the survey (mean age: 24.8 years, $55 \%$ female), with $65 \%$ enrolled at public universities. The overall prevalence of cervical pain was $41 \%$, and the corresponding prevalence for lumbar pain was $32 \%$. Female participants had significantly higher odds of reporting cervical pain [odds ratio (OR): 2.02, $p<0.001$ ]. Participants who typically avoid excessive bending and twisting were significantly less likely to report cervical pain and lumbar pain (OR: $0.51, p<0.001$, and $0.46, p<0.0001$, respectively).

Conclusion: Cervical pain and lumbar pain are highly prevalent among Saudi dental interns. Female sex was identified as a potential risk factor for cervical pain, and avoiding bending and twisting during dental work was identified as a protective factor for cervical and lumbar pain.

Clinical significance: Our results indicate that cervical and lumbar pain represent relevant health issues for dental students. Our data add further support to the notion that dental schools should consider enhancing training on dental ergonomics, enabling healthier careers for future dentists in Saudi Arabia.
\end{abstract}

Keywords: Dental students, Lower back pain, Musculoskeletal disorders, Neck pain.

The Journal of Contemporary Dental Practice (2021): 10.5005/jp-journals-10024-3160

\section{INTRODUCTION}

Musculoskeletal disorders (MSDs), such as cervical and lumbar pain, are typically provoked by the accumulation of minor injuries on the muscles, nerves, joints, and spinal disks. Epidemiological studies indicate that MSDs represent the most frequent cause of disability globally, ${ }^{1,2}$ resulting in a significant economic burden to healthcare systems worldwide. ${ }^{3}$

Emerging evidence from developed ${ }^{4}$ and developing ${ }^{5}$ countries shows that MSDs are associated with increased healthcare expenditures and a significant excess in productivity loss each year. For example, in Sweden, Gedin et al. demonstrated that the average productivity loss per individual with back pain was more than two times higher than control individuals (U\$10,500 vs \$4130) per year. ${ }^{4}$ In Brazil, Carregaro et al. ${ }^{5}$ concluded that back pain was associated with mean absenteeism of 88 days per year, whereas in the United States, the economic burden associated with neck and back disorders was estimated to reach up to U\$86 billion every year. ${ }^{6}$

Besides being a cause of enormous societal costs, MSDs can also impact mortality risk. A recent meta-analysis of 14 cohort studies suggests that back pain could be associated with a modestly elevated risk of all-cause mortality with potential higher effects among women than men. ${ }^{7}$ As a result, over the past decade, a large body of evidence has proposed that MSDs should be considered crucial health and research priorities. ${ }^{5,8}$

Among health professionals, dentists are considered one of the professional categories most likely to develop MSDs. The daily
Department of Pediatric Dentistry and Orthodontics, College of Dentistry, King Saud University, Riyadh, Saudi Arabia

Corresponding Author: Ayman M Sulimany, Department of Pediatric Dentistry and Orthodontics, College of Dentistry, King Saud University, Riyadh, Saudi Arabia, e-mail: asulimany@ksu.edu.sa

How to cite this article: Sulimany AM. Cervical and Lumbar Pain among Dental Interns in Saudi Arabia: A National Cross-sectional Study. J Contemp Dent Pract 2021;22(8):860-866.

Source of support: Nil

Conflict of interest: None

routine of these professionals usually requires prolonged static postures as well as forceful and repetitive movements. A previous systematic review showed that the prevalence of MSDs among dental professionals could range from $64-93 \%$, and the most commonly affected body sites are the back (36.3-60.1\%) and neck $(19.8-85 \%){ }^{9}$

Cervical and lumbar pain can become recurrent or chronic conditions, leading to persistent discomfort and/or pain, decreased range of motion, decreased productivity, increased absenteeism rate, frequently culminating in severe physical disability, and premature retirement among dentists. ${ }^{10}$ Early diagnosis and management of these conditions can help in preventing their progression. Several preventive measures can be taken in this

(0) The Author(s). 2021 Open Access This article is distributed under the terms of the Creative Commons Attribution 4.0 International License (https://creativecommons. org/licenses/by-nc/4.0/), which permits unrestricted use, distribution, and non-commercial reproduction in any medium, provided you give appropriate credit to the original author(s) and the source, provide a link to the Creative Commons license, and indicate if changes were made. The Creative Commons Public Domain Dedication waiver (http://creativecommons.org/publicdomain/zero/1.0/) applies to the data made available in this article, unless otherwise stated. 
regard, such as practicing stretching exercises after finishing dental work, performing clinical procedures with magnifying loupes, avoiding excessive bending and twisting for improved oral accessibility, avoiding repetitive movements, and positioning the operator chair to maintain an ergonomic posture. ${ }^{11}$

MSDs symptoms have also been observed among dental students, indicating that these disorders may arise from working habits acquired early during clinical training. ${ }^{12,13}$ However, limited data exist on the prevalence and the risk factors for cervical and lumbar pain among this specific population. With the pressures of academic achievement on top of the physical demands of clinical training faced by dental students, the question of whether cervical and lumbar pain develop during undergraduate dental education should be assessed. Therefore, we conducted a large national survey, in which we investigated the prevalence of these specific MSDs subtypes and the associated ergonomic and sociodemographic risk factors among dental interns in Saudi Arabia.

\section{Materials and Methods}

\section{Study Design and Participants}

We performed a nationwide, cross-sectional study involving dental interns who graduated during the 2018-2019 academic year from all public and private dental schools in Saudi Arabia. The study was approved by the Institutional Review Board (IRB) and the College of Dentistry Research Center (CDRC) of King Saud University. We followed the recommendations of the Strengthening the Reporting of Observational Studies in Epidemiology (STROBE) guidelines. ${ }^{14}$

\section{Procedures and Variables}

We contacted all dental interns graduating during the 2018-2019 cycle via email for study participation. We distributed self-report surveys using the Survey Monkey online platform to all eligible participants. Emails were sent from January to March 2019, and the survey was closed on March 31, 2019. Participants were contacted via a two-stage process. First, we obtained a list of all dental schools in Saudi Arabia and contacted interns' coordinators to explain the study's objective. Out of 27 dental schools in Saudi Arabia, 23 schools had dental interns during the 2018-2019 academic year. Second, upon agreement, the survey link was sent internally to all eligible dental interns. Participants received the link to the survey along with a description of the survey's purposes. To increase participation rates, interns' coordinators periodically sent reminder emails to dental interns. In total, three reminders were sent $(2,4$, and 6 weeks after the initial contact).

\section{Participants}

To be eligible, participants had to meet the following criteria: (i) regularly enrolled at a dental program in Saudi Arabia and (ii) willingness to participate in the survey.

We excluded participants with a history of scoliosis, kyphosis, those at risk of lumbar degenerative disk disease, lower extremity muscle tear, or previous disk herniation surgery. We also excluded interns who were pregnant for more than 24 weeks.

\section{Survey Tool and Variables}

The survey was written in English and included 30 closed-ended questions divided into three sections. We improved the survey with support from a panel of healthcare professionals, including specialists in occupational medicine, statistics, and oral health. In addition, we pilot tested and updated the survey based on the suggestions from a convenience sample, which included 10 interns who were not used in the final analyses. During pilot testing, we estimated the time to complete the survey and asked participants questions regarding the clarity of the questionnaires.

The first section collected sociodemographic characteristics, such as age, sex, height, and weight. Also included were pregnancy status (if appropriate), handedness, weekly exercise frequency, and type of dental school (private vs public).

The second section gathered information on participants' preventive ergonomic practices. This included posture awareness, practicing stretching exercises after finishing dental work, performing clinical procedures with magnifying loupes, avoiding excessive bending and twisting for improved oral accessibility, and positioning the chair to maintain an ergonomic posture.

The third section evaluated the prevalence of MSDs among the participants. For the latter, we used the revised version of the Standardized Nordic Musculoskeletal Questionnaire (SNQ), ${ }^{15}$ a validated instrument for assessing the prevalence of MSDs. The SNQ assesses general and regional musculoskeletal symptoms, such as pain, discomfort, or numbness, and has been widely used in studies of MSDs in several medical specialties. Participants were asked if they had any musculoskeletal symptoms in the previous 12 months. Musculoskeletal symptoms were defined as self-reported functional limitations, pain, discomfort, burning, or numbness in any of nine body areas. A human body diagram with nine symptom sites (cervical, shoulders, upper back, elbows, low back, wrist/hands, hips/thighs, knees, and ankle/feet) was shown in case of a positive response. Participants were then asked to identify the areas where they had MSDs-related symptoms. Multiple choices were allowed.

We categorized participants according to their body mass index (BMI) in $\mathrm{kg} / \mathrm{m}^{2}$ as follows: underweight (BMI $<18.5 \mathrm{~kg} / \mathrm{m}^{2}$ ), normal weight (BMI $\left.\geq 18.5-24.9 \mathrm{~kg} / \mathrm{m}^{2}\right)$, overweight $\left(B M I \geq 25-29.9 \mathrm{~kg} / \mathrm{m}^{2}\right.$ ), or obesity $\left(B M I \geq 30 \mathrm{~kg} / \mathrm{m}^{2}\right)$.

\section{Statistical Analysis}

We summarized continuous variables as means [standard deviations (SD)] and categorical variables as numbers (percentages). We tested whether there was an association between categorical variables and the presence of MSDs symptoms with a Chi-squared test. Additionally, we built multivariate logistic regression models to predict MSDs using a combination of two or more variables. Multivariate models were constructed based on the bivariate analyses, in which factors with $p<0.10$ in the bivariate analyses were exported into the final model. We considered statistically significant results with a twosided $p<0.05$. All analyses were carried with the statistical package SAS 9.4 (SAS Institute Inc., Cary, North Carolina, United States).

\section{Results}

\section{Participant Characteristics}

From January to March 2019, we contacted a total of 1,552 dental interns from 23 dental schools to participate in this study; of those, 889 (57\%) completed the survey. Ninety-five had previous medical conditions and were excluded from subsequent analyses (Flowchart 1). Thus, the final analyses included a total of 794 participants.

Table 1 provides descriptive characteristics of the included participants. Overall, 55\% were female, with a mean age of 24.8 years. About two-thirds were enrolled at public dental school (65\%) and $90 \%$ were right-handed. 
Flowchart 1: Study flowchart. ${ }^{*}$ Defined as a history of scoliosis, kyphosis, those at risk of lumbar degenerative disk disease, lower extremity muscle tear, or previous disk herniation surgery

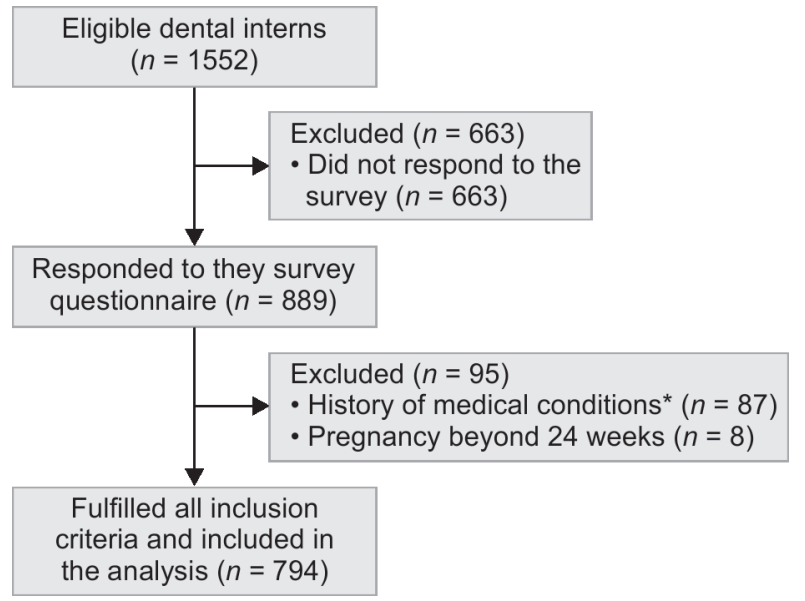

Table 1: Sociodemographic characteristics of the study participants $(n=794)$

\begin{tabular}{lc}
\hline Variables & Mean (SD) or No. (\%) \\
\hline Age (years), mean (SD) & $24.8(1.2)$ \\
Female, no. (\%) & $435(54.8)$ \\
Body mass index (BMI, kg/m²) status, no. (\%) & \\
$\quad<18.5$ & $51(6.4)$ \\
$18.5-25$ & $476(60)$ \\
$25-30$ & $196(24.7)$ \\
$>30$ & $70(8.8)$ \\
Dominant hand, no. (\%) & \\
$\quad$ Right & $703(88.5)$ \\
Left & $78(9.8)$ \\
$\quad$ Both & $13(1.6)$ \\
Exercise, no. (\%) & \\
$\quad$ Never & $386(48.6)$ \\
$\quad$ twice per week & $119(15)$ \\
2-3 times per week & $175(22)$ \\
$\quad>3$ times per week & $114(14.4)$ \\
Type of dental school & \\
Governmental & $518(65.2)$ \\
Private & $276(34.8)$ \\
\hline One participant with missing data for BMI &
\end{tabular}

\section{Prevalence of MSDs}

Among the 794 included participants, 431 (54.3\%) reported MSDs symptoms during the previous 12 months: cervical pain was reported by 325 (40.9\%) participants and 253 (31.9\%) dental interns reported lumbar pain (Fig. 1).

\section{Risk Factors for MSDs}

Table 2 summarizes the bivariate associations between cervical and lumbar pain with sociodemographic characteristics. Overall, cervical pain was 1.6 times more frequent among females than males (49.7 vs $30.4 \%$, respectively, $p<0.001$ ). Similar results were observed for lumbar pain, although the results were only marginally significant (34.7 vs $28.4 \%, p=0.06$ ). Our data also suggested that the prevalence of cervical pain might be higher among dental interns enrolled in private universities than those enrolled in public institutions (46.7 vs $37.8 \%$, respectively, $p=0.015$ ).

As expected, ergonomics awareness and preventive working practices were significantly associated with the odds of reporting MSDs symptoms (Table 3). Our results demonstrated that those participants who are aware of their posture during clinical procedures, perform stretching exercises after finishing dental work, or avoid excessive bending and twisting were significantly less likely to report cervical pain [odds ratio (OR): $0.68,95 \%$ confidence interval (Cl): $0.47-0.99, p=0.046$, OR: $0.67,95 \% \mathrm{Cl}: 0.49-0.90$, $p=0.008$, and OR: 0.45, 95\%: 0.33-0.62, $p<0.0001$, respectively]. We also detected inverse associations between performing stretching exercises and avoiding bending and stretching during clinical procedures with a reduced odd of lumbar pain. (OR: $0.74,95 \% \mathrm{Cl}$ : $0.54-1.01, p=0.057$ and OR: $0.44,95 \% \mathrm{Cl}: 0.32-0.60, p<0.0001$, respectively).

\section{Multivariate Models}

Table 4 shows the results of our multivariate logistic regression model for cervical pain that included gender, type of dental school, awareness of posture, performing stretching exercises after finishing dental work, and avoidance of bending and twisting during dental procedures. Remained statistically significant independent predictors of cervical pain are the habit of avoiding bending and twisting (OR: $0.51,95 \% \mathrm{Cl}: 0.37-0.70, p<0.0001)$. and female sex (OR: $2.02,95 \% \mathrm{Cl}: 1.49-2.74, p<0.0001)$.

Table 5 shows the corresponding multivariate logistic regression for lumbar pain, including sex, the habit of performing stretching exercises after finishing dental work, and avoiding bending and twisting during dental procedures. Only the latter remained a statistically significant independent predictor of lumbar pain (OR: $0.46,95 \% \mathrm{Cl}$ : $0.33-0.63, p<0.0001)$.

\section{Discussion}

Our findings reveal that approximately $41 \%$ of dental interns reported experiencing cervical pain and $32 \%$ reported lumbar pain in the previous year, raising concerns for the future occupational health of these professionals. Overall, female participants had a higher chance of cervical pain. Interestingly, we found that avoiding bending and twisting during dental work was a consistent independent protective factor identified in both bivariate and multivariate analyses.

Over the past decades, a large body of evidence has indicated that MSDs are a major work-related problem and one of the leading causes of disability among dental professionals and students, resulting in reduced productivity and early retirement. ${ }^{9}$ In this respect, it has been indicated that the cervical and the lumbar as the most prevalent regions for pain. 11,13,16,17 Our results concur with this notion, indicating that approximately $41 \%$ of dental interns in Saudi Arabia experienced cervical and $32 \%$ experienced lumbar pain in the previous year. This prevalence is in line with the results of Hayes et al. in Australia, ${ }^{17}$ Rising et al. in the United States, ${ }^{18}$ and Vijay and Ide in the United Kingdom, ${ }^{11}$ who reported prevalence of neck-related pain ranging from $50-64 \%$ and lower back-related pain between 37 and 54\% among dental undergraduate students. According to previous studies, measures of muscle activation patterns confirmed that dentistry work generates a high muscular load on the trapezius muscle, ${ }^{18}$ mainly due to forward bending of the head. ${ }^{19}$ It has also been recently suggested that the direct view technique may impose 


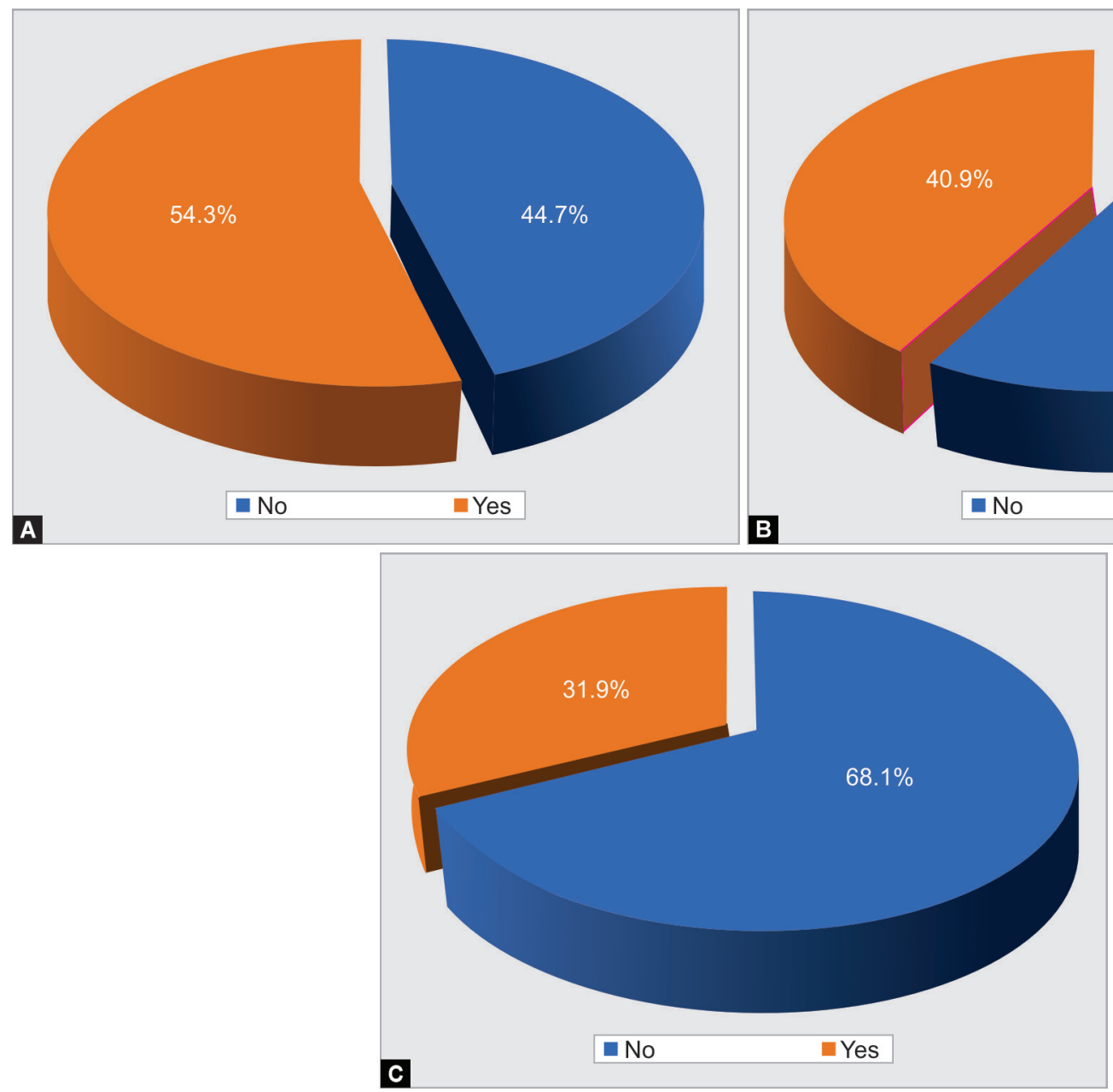

Figs 1 A to C: Prevalence of MSD among study participants: (A) Prevalence of overall MSD; (B) Prevalence of cervical pain; (C) Prevalence of lumbar pain

a considerable burden on the lower back, shoulders, and neck. ${ }^{20}$ These observations might explain why cervical and lumbar regions are typically the most affected body areas.

Several lines of evidence have proposed sex differences of musculoskeletal pain in the general population, ${ }^{21,22}$ in which women are more vulnerable to MSDs than men. Our results are strongly consistent with that accumulating evidence. We identified that sex was strongly associated with the prevalence of cervical pain, with female dental interns being twice more likely to report cervical pain than their male counterparts.

Physical exercise can improve musculoskeletal and cardiovascular functions, and it has been reported as a protective measure against the development of MSDs among dental professionals. ${ }^{23}$ For example, according to Peros et al., final-year dental students in Croatia who exercised more regularly had significantly lower lumbar pain levels than their less physically active colleagues. ${ }^{24}$ In contrast to their results, our study detected no association between physical activity and musculoskeletal pain. Differences between the previous study and ours might be attributed to study design and collection of information. While participants of this study provided self-reported information on physical activity, assessments of the earlier study relied on introducing a physical fitness program into the dental curriculum, which can provide more accurate results on the effect of exercise.
While we also found no association between the practice of stretching exercises after treating dental patients and the incidence of cervical and lumbar pain, our analyses contribute to the evidence that avoiding bending and twisting can help to prevent pain in those regions. The daily work of dental professionals involves repetitive and prolonged movements through static postures that require repeated contractions and can cause muscle shortening. While providing care, these professionals also frequently adopt awkward body postures, which predispose them to develop muscle imbalances. ${ }^{20,25}$ Thus, our findings indicate that having healthy habits can minimize the detrimental physiological changes caused by the work routine. ${ }^{26}$ However, the efficacy of this preventive strategy highly depends on the individual's education and their incorporation into practice. In this regard, we demonstrated that ergonomics awareness and preventive working practices were significantly associated with the odds of reporting MSDs symptoms. Altogether, these observations emphasize the relevance of providing proper preventive education on postural and positioning strategies, the use of ergonomic equipment, and stretching and strengthening techniques during dental training.

Our study has some limitations that are noteworthy. First, our analyses were based on self-reported information. Thus, we cannot eliminate the influence of memory (recall) bias. However, the revised version of the SNQ was used, which is a reliable tool and improves 
Table 2: Association between sociodemographic variables with cervical and lumbar pain

\begin{tabular}{|c|c|c|c|c|c|c|}
\hline \multirow[b]{2}{*}{ Variables } & \multicolumn{3}{|c|}{ Cervical pain } & \multicolumn{3}{|c|}{ Lumbar pain } \\
\hline & $\begin{array}{c}\text { No } \\
(n=469)\end{array}$ & $\begin{array}{c}\text { Yes } \\
(n=325)\end{array}$ & $p$ & $\begin{array}{c}\text { No } \\
(n=541)\end{array}$ & $\begin{array}{c}\text { Yes } \\
(n=253)\end{array}$ & $p$ \\
\hline Age (years), mean (SD) & $24.83(1.26)$ & $24.80(1.55)$ & 0.69 & $24.79(1.23)$ & $24.87(1.18)$ & 0.44 \\
\hline \multicolumn{7}{|l|}{ Gender, no. (\%) } \\
\hline Male & $250(69.64)$ & $109(30.36)$ & \multirow{2}{*}{$<0.001$} & 257 (71.59) & $102(28.41)$ & \multirow{2}{*}{0.06} \\
\hline Female & $219(50.34)$ & $216(49.66)$ & & $284(65.29)$ & $151(34.71)$ & \\
\hline \multicolumn{7}{|l|}{ Weight status, no. (\%) } \\
\hline Less than healthy (BMI <18.5) & $34(66.67)$ & $17(33.33)$ & \multirow{4}{*}{0.21} & $37(72.55)$ & $14(27.45)$ & \multirow{4}{*}{0.89} \\
\hline Healthy $(18.5 \leq \mathrm{BMI} \leq 25)$ & $268(56.30)$ & $208(43.70)$ & & $323(67.86)$ & $153(32.14)$ & \\
\hline Overweight $(25<\mathrm{BMI} \leq 30)$ & $125(63.78)$ & $71(36.22)$ & & $132(67.35)$ & $64(32.65)$ & \\
\hline Obese $(\mathrm{BMI}>30)$ & $42(60.00)$ & $28(40.00)$ & & $49(70.00)$ & $21(30.00)$ & \\
\hline \multicolumn{7}{|l|}{ Dominant hand, no. (\%) } \\
\hline Right & $416(59.17)$ & $287(40.83)$ & \multirow{3}{*}{0.95} & $479(68.14)$ & $224(31.86)$ & \multirow{3}{*}{0.99} \\
\hline Left & $45(57.69)$ & $33(42.31)$ & & $53(67.95)$ & $25(32.05)$ & \\
\hline Both & $8(61.54)$ & $5(38.46)$ & & $9(69.23)$ & $4(30.77)$ & \\
\hline \multicolumn{7}{|l|}{ Exercise, no. (\%) } \\
\hline Never & $224(58.03)$ & $162(41.97)$ & \multirow{4}{*}{0.85} & $258(66.84)$ & $128(33.16)$ & \multirow{4}{*}{0.57} \\
\hline Less than two times a week & $74(62.18)$ & $45(37.82)$ & & $85(71.43)$ & $34(28.57)$ & \\
\hline Two to three times a week & $102(58.29)$ & $73(41.71)$ & & $124(70.86)$ & $51(29.14)$ & \\
\hline Four or more times a week & $69(60.53)$ & 45 (39.47) & & $74(64.91)$ & $40(35.09)$ & \\
\hline \multicolumn{7}{|l|}{ Type of dental school, no. (\%) } \\
\hline Public & $322(62.16)$ & $196(37.84)$ & \multirow{2}{*}{0.015} & $354(68.34)$ & $164(31.66)$ & \multirow{2}{*}{0.87} \\
\hline Private & $147(53.26)$ & 129 (46.74) & & $187(67.75)$ & $89(32.25)$ & \\
\hline
\end{tabular}

Table 3: Bivariable associations between ergonomics preventive practices and cervical and lumbar pain

\begin{tabular}{|c|c|c|c|c|}
\hline \multirow[b]{2}{*}{ Variables } & \multicolumn{2}{|c|}{ Cervical pain } & \multicolumn{2}{|c|}{ Lumbar pain } \\
\hline & $O R$ & $95 \% \mathrm{Cl}$ & OR & $95 \% \mathrm{Cl}$ \\
\hline \multicolumn{5}{|c|}{ Awareness of posture during clinical procedures } \\
\hline Yes vs no & 0.68 & $0.47,0.99$ & 0.87 & $0.59,1.30$ \\
\hline \multicolumn{5}{|c|}{ Performing stretching exercises after finishing dental work } \\
\hline Yes vs no & 0.67 & $0.49,0.90$ & 0.74 & $0.54,1.01$ \\
\hline \multicolumn{5}{|c|}{ Using magnifying loupes during dental procedures } \\
\hline Yes vs no & 0.93 & $0.69,1.24$ & 1.01 & $0.75,1.38$ \\
\hline \multicolumn{5}{|c|}{ Avoid bending and twisting during dental procedures } \\
\hline Yes vs no & 0.45 & $0.33,0.62$ & 0.44 & $0.32,0.60$ \\
\hline \multicolumn{5}{|c|}{ Positioning operator chair to maintain an ergonomic posture } \\
\hline Yes vs no & 0.84 & $0.58,1.21$ & 0.92 & $0.63,1.35$ \\
\hline
\end{tabular}

Table 4: Multivariate logistic regression model for factors associated with cervical pain

\begin{tabular}{llcr}
\hline & \multicolumn{2}{c}{ Cervical pain } & \\
\cline { 2 - 3 } & Variables & $95 \% \mathrm{Cl}$ & p value \\
\hline $\begin{array}{l}\text { Gender } \\
\quad \text { Female vs male }\end{array}$ & 2.02 & $1.49,2.74$ & $<0.0001$ \\
$\begin{array}{l}\text { Type of dental school } \\
\quad \text { Private vs governmental }\end{array}$ & 1.18 & $0.86,1.63$ & 0.30 \\
$\begin{array}{l}\text { Aware of posture } \\
\quad \text { Yes vs no }\end{array}$ & & & \\
$\begin{array}{l}\text { Perform stretching exercises after finishing dental work } \\
\quad \text { Yes vs no }\end{array}$ & 0.80 & $0.53,1.22$ & 0.30 \\
$\begin{array}{l}\text { Avoid bending and twisting during dental procedures } \\
\quad \text { Yes vs no }\end{array}$ & 0.83 & $0.60,1.15$ & 0.25 \\
\hline
\end{tabular}


Table 5: Multivariate logistic regression model for factors associated with lumbar pain

\begin{tabular}{|c|c|c|c|}
\hline \multirow[b]{2}{*}{ Variables } & \multicolumn{2}{|c|}{ Lumbar pain } & \multirow[b]{2}{*}{$p$ value } \\
\hline & OR & $95 \% \mathrm{Cl}$ & \\
\hline \multicolumn{4}{|l|}{ Gender } \\
\hline Female vs male & 1.18 & $0.86,1.62$ & 0.29 \\
\hline \multicolumn{4}{|c|}{ Perform stretching exercises after finishing dental work } \\
\hline Yes vs no & 0.80 & $0.58,1.10$ & 0.17 \\
\hline \multicolumn{4}{|c|}{ Avoid bending and twisting during dental procedures } \\
\hline Yes vs no & 0.46 & $0.33,0.63$ & $<0.0001$ \\
\hline
\end{tabular}

the comparability of ours results with previous investigations. Second, our sample is not entirely probabilistic. Although we contacted all dental interns graduating during the 2018-2019 cycle, we included only participants willing and able to complete the questionnaires. However, given the relatively large sample size, our investigation is likely to be valid for the Saudi setting in general (i.e., high internal validity). Moreover, assessing the MSDs among this specific population could be the best way to reflect the impact of lack of occupational health education in the undergraduate dental curriculum. Third, as with any cross-sectional study, confounding is probable, and results represent a snapshot of the studied population during the 2018-2019 academic year. Our data could not assess temporal trends and the long-term consequences of MSDs symptoms during dental school. Prospective investigations with standardized data collection will be of paramount importance to examine the longitudinal changes and the incidence of workrelated MSDs in the studied population.

\section{ConcLusion}

We conclude that cervical and lumbar pain represent relevant health issues for dental students in Saudi Arabia. Our data add further support to the notion that dental schools should carefully consider enhancing training on dental ergonomics, enabling longer and healthier careers for the next generation of dental professionals in Saudi Arabia.

\section{ACKNOWLedgment}

Author would like to thank the Deanship of Scientific Research and the College of Dentistry Research Center at King Saud University, Saudi Arabia, for the support in conducting this research.

\section{REFERENCES}

1. Hoy $D$, March $L$, Brooks $P$, et al. The global burden of low back pain: estimates from the Global Burden of Disease 2010 study. Ann Rheum Dis 2014;73(6):968-974. DOI: 10.1136/annrheumdis-2013-204428.

2. Hoy $D$, March $L$, Woolf $A$, et al. The global burden of neck pain: estimates from the global burden of disease 2010 study. Ann Rheum Dis 2014;73(7):1309-1315. DOI: 10.1136/annrheumdis-2013-204431.

3. Dagenais S, Caro J, Haldeman S. A systematic review of low back pain cost of illness studies in the United States and internationally. Spine J 2008;8(1):8-20. DOI: 10.1016/j.spinee.2007.10.005.

4. Gedin F, Alexanderson K, Zethraeus N, et al. Productivity losses among people with back pain and among population-based references: a register-based study in Sweden. BMJ Open 2020;10(8):e036638. DOI: 10.1136/bmjopen-2019-036638.

5. Carregaro RL, Tottoli CR, Rodrigues DD, et al. Low back pain should be considered a health and research priority in Brazil: lost productivity and healthcare costs between 2012-2016. PLoS One 2020;15(4):e0230902. DOI: 10.1371/journal.pone.0230902.

6. Martin BI, Deyo RA, Mirza SK, et al. Expenditures and health status among adults with back and neck problems. JAMA 2008;299(6):656664. DOI: 10.1001/jama.299.6.656.

7. Roseen EJ, Rajendran I, Stein P, et al. Association of back pain with mortality: a systematic review and meta-analysis of cohort studies. J Gen Intern Med 2021:1-1. DOI: 10.1007/s11606-021-06732-6.

8. Buchbinder $R$, van Tulder $M$, Öberg $B$, et al. Low back pain: a call for action. Lancet 2018;391(10137):2384-2388. DOI: 10.1016/S01406736(18)30488-4.

9. Hayes MJ, Cockrell D, Smith DR. A systematic review of musculoskeletal disorders among dental professionals. Int J Dent Hyg 2009;7(3):159165. DOI: 10.1111/j.1601-5037.2009.00395.x.

10. Valachi B, Valachi K. Mechanisms leading to musculoskeletal disorders in dentistry. J Am Dent Assoc 2003;134(10):1344-1350. DOI: 10.14219/ jada.archive.2003.0048.

11. Gaowgzeh RA, Chevidikunnan MF, Al Saif A, et al. Prevalence of and risk factors for low back pain among dentists. J Phys Ther Sci 2015;27(9):2803-2806. DOI: 10.1589/jpts.27.2803.

12. Vijay S, Ide M. Musculoskeletal neck and back pain in undergraduate dental students at a UK dental school-a cross-sectional study. $\mathrm{Br}$ Dent J 2016;221(5):241-245. DOI: 10.1038/sj.bdj.2016.642.

13. Leggat PA, Kedjarune U, Smith DR. Occupational health problems in modern dentistry: a review. Ind Health 2007;45(5):611-621. DOI: 10.2486/indhealth.45.611.

14. Von Elm E, Altman DG, Egger M, et al. The Strengthening the Reporting of Observational Studies in Epidemiology (STROBE) statement: guidelines for reporting observational studies. Bull World Health Org 2007;85(11):867-872. DOI: 10.2471/BLT.07.045120.

15. Kuorinka I, Jonsson B, Kilbom A, et al. Standardised Nordic questionnaires for the analysis of musculoskeletal symptoms. Appl Ergon 1987;18(3):233-237. DOI: 10.1016/0003-6870(87)90010-x.

16. Hayes MJ, Smith DR, Cockrell D. Prevalence and correlates of musculoskeletal disorders among Australian dental hygiene students. Int J Dent Hyg 2009;7(3):176-181. DOI: 10.1111/j.16015037.2009.00370.x.

17. Rising DW, Bennett BC, Hursh K, et al. Reports of body pain in a dental student population. J Am Dent Assoc 2005;136(1):81-86. DOI: 10.14219/jada.archive.2005.0032.

18. Milerad E, Ericson MO, Nisell R, et al. An electromyographic study of dental work. Ergonomics 1991;34(7):953-962. DOI: 10.1080/00140139108964837.

19. Jonker D, Rolander B, Balogh I. Relation between perceived and measured workload obtained by long-term inclinometry among dentists. Appl Ergonom 2009;40(3):309-315. DOI: 10.1016/j.apergo.2008.12.002.

20. Katano K, Nakajima K, Saito M, et al. Effects of line of vision on posture, muscle activity and sitting balance during tooth preparation. Int Dent J 2021;S0020-6539(20)36556-4. DOI: 10.1016/j.identj.2020.12.025.

21. Rollman GB, Lautenbacher S. Sex differences in musculoskeletal pain. Clin J Pain 2001;17(1):20-24. DOI: 10.1097/00002508-200103000-00004.

22. Wijnhoven HA, De Vet HC, Picavet HS. Prevalence of musculoskeletal disorders is systematically higher in women than in men. Clin J Pain 2006;22(8):717-724. DOI: 10.1097/01.ajp.0000210912.95664.53. 
23. Kumar DK, Rathan N, Mohan S, et al. Exercise prescriptions to prevent musculoskeletal disorders in dentists. J Clin Diagn Res 2014;8(7):ZE13. DOI: $10.7860 / J C D R / 2014 / 7549.4620$.

24. Peros $K$, Vodanovic M, Mestrovic S, et al. Physical fitness course in the dental curriculum and prevention of low back pain. J Dent Educ 2011;75(6):761-767. DOI: 10.1002/j.0022-0337.2011.75.6.tb05103.x.
25. Pîrvu C, Pătraşcu I, Pîrvu D, et al. The dentist's operating postureergonomic aspects. J Med Life 2014;7(2):177. Available from https:/ www.ncbi.nlm.nih.gov/pmc/articles/PMC4151237/

26. De Sio S, Traversini V, Rinaldo F, et al. Ergonomic risk and preventive measures of musculoskeletal disorders in the dentistry environment: an umbrella review. Peer J 2018;6:e4154. DOI: 10.7717/peerj.4154. 